\title{
DESCOLONIZAR A FILOSOFIA BRASILEIRA: DESAFIOS ÉTICOS E POLÍTICOS PARA AS FILOSOFIAS DO SUL GLOBAL
}

\author{
Rodrigo Pelloso Gelamo ${ }^{1}$ \\ Amanda Veloso Garcia ${ }^{2}$ \\ Augusto Rodrigues ${ }^{3}$
}

Resumo: O objetivo deste artigo é problematizar algumas das principais práticas da filosofia universitária brasileira, de forma a denunciar seus pressupostos colonizadores e apontar seus limites na elaboraçấo de um pensamento filosófico capaz de se relacionar, efetivamente, com os problemas do território brasileiro. Analisa-se como a estratégia de leitura e explicação dos textos europeus e estadunidenses, considerados predominantemente as referências clássicas à filosofia, faz funcionar as relaçóes de saber e dominação existentes do Norte global sobre os povos do Sul por eles colonizados. Utilizase a experiência constitutiva do curso de filosofia da Universidade de Sáo Paulo como exemplo das práticas e dos pressupostos de colonialidade pelos quais nossa filosofia acadêmica é modelada. A partir das contribuiçốes de Lélia Gonzalez (1988), Ailton Krenak (2019), Silvia Rivera Cusicanqui (2010) e Leanne Betasamosake Simpson (KLEIN, 2012), serão questionados essas práticas e pressupostos, demonstrando como tais autores desafiam não só a alterar o habitual referencial teórico naturalizado na filosofia brasileira, mas, principalmente, a operar uma mudança ética e política nas relaçôes que se estabelecem, usualmente, com a filosofia.

Palavras-chave: Filosofia brasileira. Colonialidade. Práticas universitárias. Historiografia.

${ }^{1}$ Professor do Departamento de Didática e dos Programas de Pós-Graduação em Educação e Filosofia da Universidade Estadual Paulista (UNESP), Marília, SP - Brasil. (D) https://orcid.org/0000-00031532-3243. E-mail: rodrigo.gelamo@unesp.br.

2 Professora de Filosofia no Instituto Federal do Rio de Janeiro (IFRJ), Rio de Janeiro, RJ - Brasil.

(D) https://orcid.org/0000-0002-4959-8256. E-mail: amanda.garcia@ifrj.edu.br.

3 Doutorando em Educação na Universidade Estadual Paulista (UNESP), Marília, SP - Brasil.

(D) https://orcid.org/0000-0003-2574-9897. E-mail: augusto.rodrigues@unesp.br.

https://doi.org/10.1590/0101-3173.2022.v45esp.20.p415

\section{(i)}


A filosofia, no Brasil, tem sido sobretudo história da filosofia. (RIBEIRO, 2005, p. 89).

\section{INTRODUÇÃo}

A chamada de artigos para o número especial da Revista Trans/form/ ação, responsável por alçar o debate sobre a "Filosofia(s) do Sul: entre a África e a América Latina", vem em momento oportuno. Evidencia uma possibilidade de perspectivar a filosofia de maneira diversa daquela comumente praticada na universidade. A filosofia feita no Brasil diz pouco ou quase nada sobre o território em que emerge, principalmente pelo conjunto de práticas e pressupostos que a modelam no cenário contemporâneo. Isso não nos permite que estejamos conectados com os acontecimentos urgentes do presente.

A divisão abissal entre o que Santos (2010) entende por epistemologias do Sul e aquilo que poderíamos conceber por epistemologias do Norte, em quem a chamada parece se inspirar, é consequência do projeto imperial do colonialismo, instaurado como uma prática histórica nas terras invadidas pelos europeus. Não diz respeito exclusivamente à localização geográfica, mas à exclusão de povos e de culturas, que foram submetidos à cultura e conhecimento de mundo dos dominadores. Marcados por esse registro, procuraremos colocar nosso problema em uma perspectiva ético-política, de forma a destacar a permanência e a capilarização dos processos de imperialidade (BALLESTRIN, 2017) e colonialidade (QUIJANO, 2005), em nosso território e instituiçóes, que ainda dão continuidade a essas relações de poder. Partimos, inicialmente, da própria abertura da chamada, a qual nos oferece a possibilidade de olharmos para os acontecimentos de nosso território - que ocorrem em nossas circunstâncias, em nosso presente e afetam nossas vidas -, com o objetivo de "propor modelos de pensamento e de existência que partam da necessidade de uma mudança radical do paradigma atual, a que a sociedade civil poderá contribuir sobremaneira", escapando, na medida do possível, de uma perspectiva de análise histórica ou historiográfica. Essa proposta coloca em questão um posicionamento epistêmico e um modo de fazer pesquisa em filosofia que não é comum no Brasil. E é nesse lugar em que procuramos colocar nosso problema.

Problematizaremos como a insistência em uma prática de leitura e explicação de textos como estratégia exclusiva e autossuficiente da pesquisa filosófica, privilegiando um conhecimento da história da filosofia ocidental, 
é responsável pela constituição de um saber filosófico totalmente voltado para o Norte global. Embora haja, em nosso cenário acadêmico, pesquisas temáticas com a filosofia, majoritariamente propensas ao debate e à discussão de questôes, elas não costumam romper com as práticas explicativas, de forma a concentrar seus esforços, hegemonicamente, na interpretação dos autores considerados como referenciais clássicos, obscurecendo-nos, por consequência, na capacidade de discussão e debate dos problemas da realidade brasileira.

Utilizaremos a experiência constitutiva do curso de filosofia da USP como exemplo, para demonstrar alguns pressupostos e práticas colonizadoras de nossa filosofia acadêmica brasileira, debatendo-os a partir da interlocução com filósofas e filósofos não tão frequentes na universidade. Ao optarmos pela escolha da USP, não queremos universalizar sua trajetória de constituição e suas práticas hegemônicas como a única forma de ensinar, aprender e fazer filosofia na realidade brasileira. Nesse quesito, concordamos com Margutti (2013, p. 10), quando ressalta que "[...] a situação em que se insere a comunidade filosófica brasileira é bastante complexa e não se reduz facilmente a um esquema prémoldado." Mesmo assim, continua o autor, "[...] algumas características gerais podem ser apresentadas." Do mesmo modo que ele considera como tendência de nossa filosofia brasileira o interesse mais no comentário de textos do que no oferecimento de contribuiçóes autorais, emergentes de nossa realidade (MARGUTTI, 2013, p. 13), acreditamos que, por essa instituição ser um dos primeiros cursos de filosofia no Brasil, por ter desenvolvido uma tradição acadêmica referencial a algumas tendências que queremos denunciar, como referimos no parágrafo anterior, optamos por empregá-la como estratégia de análise demonstrativa de seus pressupostos.

Outro motivo especial que nos leva a analisar essa universidade é o estreito vínculo que temos com essa instituiçáo, cuja influência foi e permanece crucial em nossa formação filosófica. Denunciar tais práticas significa problematizar nosso próprio território, transformar em problema filosófico as relaçóes vitais em que permanecemos, isto é, significa exemplificarmos em ato o que pensamos ser crucial como uma estratégia ética e política descolonizantes. Quem sabe, de posse de nossas análises e experiências, os futuros leitores não encontrem, nos caminhos apresentados, interlocução, não para verificar empiricamente em um processo dedutivo o lugar e sob quais relaçóes pratica a filosofia, mas que, ao dialogar conosco, possam também experimentar as relaçóes de seu contexto e adotar sua postura ética e política. Esperamos, assim, indicar caminhos para o filosofar no Brasil, de forma a 
chamar a atenção para a necessidade de o pensamento filosófico se conectar com os problemas que urgem ser pensados em seu contexto e território.

Em nossa percepção, a influência das filosofias do Norte Global é muito grande sobre o nosso modo de fazer filosofia. Se olharmos para os Anais dos encontros da Associação Nacional de Pós-Graduação em Filosofia (ANPOF), principal congresso de pesquisa da área, notaremos que boa parte das pesquisas realizadas "[...] se recusam a pensar as questôes que hoje se colocam para a filosofia no Brasil.” (RIBEIRO, 2014, p. 148). Encaramos essa recusa como uma consequência das pesquisas filosóficas brasileiras, limitadas, em sua grande maioria, à leitura e explicação de textos clássicos da cultura europeia como prática historiográfica. O que parece ser um plausível procedimento técnico, ler os textos filosóficos, conferir o que a tradição e outras leituras atribuem a eles, ganhou autossuficiência em termos de pesquisa. A ambição dos pesquisadores em filosofia se tornou a revisão de obras filosóficas, realizando um trabalho de leitura direta dos textos, de preferências dos originais, de modo a reinterpretar os escritos dos filósofos e inovar na leitura deles.

Palácios enfatiza que, para quem vem de outro país, como é seu caso, essa tendência é muito clara e hegemônica. Desde sua primeira participação na ANPOF, percebeu que a maioria das pesquisas tinha como enfoque a explicação de determinado autor e de seus conceitos, assim como as "[...] publicaçóes e conferências sobre filosofia, escritas e lidas aqui no Brasil, mostravam seu interesse quase que exclusivamente historiográfico." (PALÁCIOS, 2003-2004, p. 2). Na tentativa de nos conectar diretamente com os filósofos consagrados, por meio desse esquema de leitura, enfraquecemos os elos possíveis com os problemas que emergem do cenário brasileiro e impedimos que nossos eventos nacionais constituam um espaço de debate público de ideias e problemas, conforme aponta Ribeiro (2014, p. 151):

A vaidade de querer ser o intérprete adequado de um ilustre falecido impede que conversemos, freia nosso diálogo e, sobretudo, bloqueia uma ágora, uma res publica, um estar juntos, a constituiçấo de uma companhia. Daí que a reunião nacional da área não passe, afinal, de uma soma de pequenas reunióes - a dos grupos de trabalho, por sinal uma ideia muito boa -, mas mesmo estas se mostrando pouco dispostas a atacar, de frente, as questóes filosóficas: o que fazem com maior frequência é mostrar que se leu direito algum pensador. E o máximo que vemos entre nós é ler 
algum pensador com alguma originalidade, mas uma originalidade de interpretação, não das ideias, da leitura, da autoria.

Essa característica de pesquisa adquire contornos ainda mais desafiadores no cenário contemporâneo. $\mathrm{O}$ enclausuramento da filosofia como domínio técnico de interpretação integra-se às exigências do conhecimento especializado, estimulando-nos a circunscrever nossas pesquisas a um registro restrito, basicamente um conhecimento aprofundado e específico sobre um autor ou filosofia. Ora, quantos de nós, indaga Palácios (2007, p. 106), conhecemos "[...] colegas que em praticamente toda sua carreira acadêmica só têm publicado trabalhos sobre as ideias de um ou, no máximo, dois filósofos? E não é precisamente isso que os organismos de apoio à pesquisa, aqueles que avaliam nossos cursos e professores, querem de nós?” Os estudantes, por sua vez, seguem os direcionamentos e os passos de seus professores. Incentivados pela concessão de bolsas científicas, são convidados a escolher as direçóes já determinadas pelas pesquisas em andamentos de seus orientadores, de forma a acelerar seus estudos na graduação e percorrer a pós-graduação com um projeto praticamente pronto e fechado. Apesar de presenciarmos um aumento significativo no número de teses e dissertaçooes defendidas, muitas vezes com pesquisas realizadas no exterior, cabe questionar o que indiciam esses números na qualidade e solução dos problemas da realidade brasileira, tendo em vista que tais pesquisas não costumam ultrapassar nossos afunilados interesses institucionais.

De fato, algumas pesquisas tentam sair desse enquadramento de especialização em um exclusivo autor ou filosofia, ao debater questóes e problemas filosóficos, por meio de um trabalho temático, o que realmente poderia contribuir para pensarmos a contemporaneidade. Mas, mesmo assim, nelas ainda prevalece uma lógica explicativa e interpretativa dos textos. Segundo assinala Ribeiro (2014, p. 148), “[...] debatemos mais autores do que ideias”; quando "[...] estas chegam a ser discutidas, o são com referência a alguns nomes", especialmente os clássicos consagrados pela filosofia europeia e, em alguns casos, os filósofos estadunidenses. ${ }^{4}$ É como se fosse uma dependência, uma adicção: a “[...] abordagem que se faz das ideias estaria viciada em nomes

\footnotetext{
${ }^{4}$ Nos estudos decoloniais, há uma longa discussão sobre a relação entre imperialidade e colonialidade, o que explica a relaçáo que certos territórios, como o brasileiro, têm com alguns países, como os Estados Unidos. Nessa perspectiva, podemos dizer que a inclusão de estadounidenses no debate acadêmico brasileiro, não constitui de uma decolonialidade do pensamento, mas pode reproduzir ainda a mesma lógica da colonialidade.
} 
próprios, mortos, distantes de nós.” Assim, a reflexão e o debate, realizados pelas filosofias acadêmicas, quando são elaborados, limitam-se à interpretação e explicação dos referenciais das filosofias do Norte, não permitindo um olhar aos problemas que emergem das nossas relaçóes com a vida e com nosso território, com aquilo que nos é comum.

Temos a impressão de que essas práticas filosóficas têm, como um de seus pressupostos, a existência de uma progressão histórica universal, cujo auge é o desenvolvimento da cultura europeia. Esse pressuposto está na base da invasão colonial e de nossas relações de colonialidade. A autoafirmação de si mesmos, como o auge da humanidade, levou os europeus a impor aos povos colonizados uma categorização de primitivo (selvagem), de maneira a fazer funcionar uma estratégia de invisibilização dos povos nativos nos territórios invadidos, submetendo-os, e nos submetendo, a uma perspectiva etnocêntrica e monocultural do conhecimento.

Mesmo com o fim das hierarquias coloniais explícitas, as relações entre colonizadores e colonizados permaneceram calcadas na mesma lógica, o que levou o peruano Aníbal Quijano a elaborar o conceito de colonialidade do poder. Esse conceito refere-se à continuidade das formas de opressão coloniais através das relações de poder, saber e acumulação de capital ${ }^{5}$, pois o modo como o mundo moderno se constitui está ancorado em um padrão de poder global “[...] colonial/moderno, capitalista e eurocentrado." (QUIJANO, 2005, p. 126). Sem a invasão europeia às Américas e a escravização de ameríndios e africanos, seria impossível que tal padrão de poder se constituísse. Foi a exploração desses territórios e sujeitos que levou, além do enriquecimento de países europeus, à ampliaçấo de sua dominação sobre o sistema-mundo dos povos colonizados. Nesse sentido, ainda nos dias de hoje, a autodeclarada universalidade do pensamento europeu torna a violência, empreendida por eles, como justa, porque se encontra devidamente justificada nas autoimagens da vida europeia como modelo.

Para melhor entender essas marcas mais recentes desse processo de colonialidade do pensamento europeu sobre a filosofia que se faz no Brasil, podemos olhar para um de seus casos mais emblemáticos: as missóes

5 "Sem a conquista da África, Ásia e América, não haveria capitalismo mundial, de maneira que estamos falando de um sistema capitalista e colonialista desde o seu nascimento. Sem colonialismo e a dominação colonial, nâo haveria mercado capitalista global. O colonialismo é constitutivo do capitalismo. Um é inerente ao outro. Dessa forma, não vivemos em um sistema puramente capitalista. Habitamos um capitalismo histórico que é inerentemente colonial e, portanto, racial." (GROSFOGUEL, 2016, p. 128, traduçâo nossa). 
universitárias francesas realizadas na Universidade de São Paulo (USP), entre as décadas de 1930 e 1960, responsáveis por cristalizar hábitos técnicoacadêmicos muito próximos do que viemos apontando e que detalharemos a seguir.

Maugüé primeiro professor de filosofia da missão a aportar nas terras brasileiras, surpreendia-se como, no Brasil, era comum ensinar filosofia sem que se lessem os filósofos. Colocando em prática os mandamentos da tradição francesa acadêmica, que considerava o conhecimento dos filósofos clássicos "os prolegômenos da filosofia futura" (MAUGÜÉ, 1955, p. 645), o professor caracterizava os filósofos como estrelas, pontos fixos da história a partir dos quais os novos navegantes em filosofia - leia-se, nesse caso, os brasileiros - encontrariam referências à construçáo de novas rotas do país em desenvolvimento. Por essa razão, o ensino de filosofia no Brasil, caso quisesse acompanhar o progresso europeu, precisaria ser principalmente histórico:

[...] a base do ensino da filosofia no Brasil é a história da filosofia. Podese perguntar qual o interesse que há para um país novo reaviver o seu trato com velhos pensadores como Platáo ou Leibniz. Serão eles que a tornaráo consciente, fazendo com que ela possa aferir o que tem ganho em poder sobre a natureza, em clareza na inteligência e em justiça na vida moral. Em navegação, a posição e as novas rotas são dadas em referência a certos astros, considerados fixos. Os filósofos clássicos são os pontos fixos da história. Se o presente não se situar exatamente em relaçáo ao passado, será como um navio que perdeu a rota. (MAUGÜÉ, 1955, p. 646).

O acento na centralidade da história da filosofia na formação filosófica - que, nesse caso, significa a leitura dos textos clássicos, já que os filósofos “[...] ainda são vivos em seus textos" (MAUGÜÉ, 1955, p. 645) - encontra sua motivação na própria característica de uma filosofia universitária reflexiva, a qual imortaliza os sistemas filosóficos e os condiciona como elementos de referência às reflexôes filosóficas na atualidade (MAUGÜÉ, 1955, p. 643). No entanto, o argumento de imortalidade da filosofia, sustentado por sua suposta universalidade e atemporalidade, serve a muitos interesses. De fato, essas diretrizes não estão isentas de pressupostos; não há qualquer neutralidade científico-universitária nelas. Ora, Maugüé não deixava de repetir as relaçóes de poder e dominação de colonialidade, condicionando os outros grupos sociais às imagens da Europa, afirmando-a como modelo de universalidade e, consequentemente, expressão da modernidade. No caso, a filosofia acadêmica francesa e seus pressupostos e práticas, principalmente a centralidade e 
autorreferência da história da filosofia ocidental como possibilidade de um filosofar futuro, serviram como modelo a ser imitado em solo brasileiro, se assim quiséssemos sair da condição de "subdesenvolvidos" ou "primitivos".

Nesse sentido, quando o professor afirma que o "senso histórico" e o "discernimento" são o que nos faltam em nossa condição de nação ainda jovem (MAUGÜÉ, 1955, p. 649), o que ele pressupóe é, dentro dos parâmetros de colonialidade, uma ausência de um conhecimento específico das ideias filosóficas eurocêntricas. Em nenhum momento se assumiu a possibilidade de um passado do nosso território, com o qual se poderia aprender com as práticas já existentes, com o pensamento já desenvolvido pelos povos nativos, mas se trata de um passado universal, cuja expressão é a Europa. Por essa razão, o argumento em torno da jovialidade do país, que busca justificar uma sobreposição cultural filosófico- europeia como saber necessário à modernidade, não se sustenta historicamente.

Com efeito, os filósofos europeus, em suas condições de bússolas norteadoras de uma futura formação filosófica a se criar, só podem ser os pontos fixos de um desenvolvimento histórico-filosófico caso se apaguem as condiçóes históricas que nos mostram a existência de inúmeros povos vivendo e pensando em nosso território, há séculos, quando os europeus o invadiram - sem mencionar ainda outras naçóes mais antigas que as ocidentais e que também são ignoradas por tais discursos. Em síntese, as diretrizes de Maugüé fizeram-se possíveis teoricamente dentro das relaçóes de colonialidade, a partir das quais as diferenças e as nuances da realidade brasileira são vistas como desigualdades naturais que precisavam ser corrigidas em favor de um ideal de humanidade "moderna".

Tal como Maugüé, Lívio Teixeira, um de seus sucessores, é também enfático ao atribuir à história da filosofia europeia a condição futura da filosofia no Brasil. Olha para a Europa como lição, como a imagem de uma cultura consolidada, desenvolvida, a serviço do país ainda em construção, que cambaleia a passos lentos na esteira do progresso e do tempo. Em suas palavras, a história da filosofia é "[...] particularmente importante para nós [brasileiros] porque, de um lado, é a única maneira de compreender bem a filosofia contemporânea; de outro lado, é a formação histórica que nos poderá dar os elementos de uma contribuição brasileira à filosofia." (TEIXEIRA, 2003, p. 199). 
Reforça ainda mais, com isso, a perspectiva etnocêntrica colonial, a qual não só desconsidera que a superior cultura europeia foi construída sobre a destruição e subjugação de outras culturas e povos, mas também tem como pressuposto uma concepção linear de história como acúmulo progressivo, em que os europeus são os únicos reconhecidos como portadores de uma Antiguidade, Idade Média, Modernidade e Contemporaneidade. Afinal, de todos os povos dos territórios invadidos são suprimidas suas próprias histórias e quaisquer mudanças sofridas por essas populaçóes, vide o exemplo da leitura europeia, por um lado, dos ameríndios - cujo imaginário colonial ainda os entende como tendo hoje as mesmas características que tinham na colonização em 1492 - e, por outro, da América Latina e da África - ambos continentes vistos como estáticos no tempo, sem história e sem filosofia -, como, inclusive, apontou Hegel (1837) acerca do continente africano.

Sustentada no funcionamento e nas capilarizaçóes institucionais das relaçóes de colonialidade, a imprescindibilidade do conhecimento da história da filosofia tornou-se um pressuposto fundamental para a constituição da filosofia brasileira futura. E, na medida em que a história da filosofia deveria ter um lugar primordial no Brasil, abriram-se as condiçôes necessárias para a recepçáo e "convivência universitária" com as "obras de Guéroult ${ }^{6}$ e Goldschmidt" (MARQUES, 2007, p. 29). Eles seriam os patronos responsáveis por inspirar e cultivar, institucionalmente, o método de análise estrutural dos textos clássicos como prática de estudo da história da filosofia. Daí em diante, conhecer a história da filosofia significaria potencializar uma prática metodológica de explicação e leitura dos textos clássicos, responsável por reconstruir, em forma de comentário, a estrutura essencial da obra filosófica. Supostamente, seria essa prática histórico-filosófica, um estudo rigoroso da história da filosofia, que garantiria um conhecimento verdadeiro dos clássicos e também se tornaria um marco de divisão na filosofia acadêmica até então praticada no cenário brasileiro, como aponta Prado Júnior (1988, p.

\footnotetext{
${ }^{6}$ Guéroult foi professor contratado da cadeira História da Filosofia, entre 15/07 e 31/12/1948, e professor visitante da mesma cadeira, de 01/08 a 30/11/1949. Já no segundo semestre de 1951, Guéroult visita a USP, ministrando duas séries de aulas: uma sobre os pré-socráticos, para o $1^{\circ}$ ano de Filosofia, outra sobre Leibniz, para o $2^{\circ}$ ano (MARQUES, 2007, p. 15-16).

${ }^{7}$ A influência de Victor Goldschmidt ocorreria principalmente pela tradução de seu livro A religião de Platão e o apêndice, Tempo histórico e tempo lógico na interpretação dos sistemas filosóficos, de forma que este último seria considerado um receituário metodológico para interpretação dos sistemas filosóficos (MARQUES, 2007, p. 21). Por outro lado, os jovens professores da década de 1960, Gianotti, Porchat, Ruy Fausto e Bento Prado Júnior, realizam um ciclo de viagens de estudos em Rennes, onde foram alunos de Victor Goldshcmidt (PRADO JÚNIOR, 1988, p. 66).
} 
67): “[...] o treinamento escolar da análise de texto aparecia espontaneamente, não só como instrumento de ascese, mas também como arma no combate à geleia geral ideológica dominante no país."

Institucionalmente, consolidava-se, na década de 1960, uma filosofia acadêmica marcada fortemente por ser um método que não se confunde nem com filosofia, nem história, mas se pratica como um "[...] viés dissertativo de explicação de texto" (ARANTES, 1994, p. 158), no qual "[...] os problemas, antes de tomarem corpo, costumam ser apenas uma maneira de dissertar.” (ARANTES, 1994, p. 27). Uma prática estritamente técnica com a filosofia, "[...] que serviu de paradigma para uma grande parte das instituiçôes universitárias brasileiras, marcando assim o presente quadro da pesquisa filosófica no país." ${ }^{8}$ No entanto, tal paradigma "[...] apresenta no momento uma série de problemas que demandam solução.” (MARGUTTI, 2014, p. 399).

Apesar de toda a aposta universitária no conhecimento da história da filosofia, enquanto prática de leitura e explicação de textos, há de se duvidar da potencialidade desse método e de suas decorrentes práticas acadêmicas para pensar os problemas da nossa realidade, emergidos em nosso território, porque, para disciplinar nossa mente filosófica rebelde, essas práticas funcionaram muito mais como uma "ideologia", uma "uniformidade metodológica" do que propriamente uma inspiração mais funda dos praticantes (PRADO JÚNIOR, 1988 , p. 68). Sem a preocupaçáo em debater os pressupostos que sustentavam os enunciados técnicos formativos, tais procedimentos histórico-filosóficos foram simplesmente apropriados como recurso propedêutico, como técnica de leitura e explicação de textos. Se em favor da história da filosofia e da metodologia estruturalista de explicação dos clássicos europeus contava a neutralidade e a objetividade de práticas universitárias filosóficas, adotava-se, também, um ensino de filosofia "[...] especializado em produzir um vácuo histórico em torno do discurso filosófico, cuja autonomia se devia preservar." (ARANTES, 1994, p. 19). Basicamente, desenvolvia-se um estudo da história da filosofia sob uma prática de duplo isolamento: o texto e o contexto da

\footnotetext{
${ }^{8}$ Mesmo que, a partir dos anos 1970, muitos jovens professores e pesquisadores brasileiros tenham feito seus estudos no exterior, em outro país que não a França, o que diversifica as influências acadêmicas no solo brasileiro, a história da filosofia e a técnica de leitura e explicação de textos clássicos marcam o cenário formativo brasileiro, como se observa em alguns documentos oficiais, tanto de graduação como da filosofia no Ensino Médio (BRASIL, 2001, 2002, 2006). Não sem motivos, as críticas produzidas dentro do debate do ensino de filosofia, no Brasil, apontam para uma tradicionalidade de práticas formativas que se centralizam na história da filosofia e no texto clássico.
} 
história do pensamento; o texto e a conexão dos clássicos europeus com os problemas que afloram da realidade social.

O que sustenta esse vácuo histórico da história da filosofia estruturalista é a ideia de racionalidade, desenvolvida na Crítica kantiana. É o sujeito transcendental responsável por permitir que as doutrinas sejam estudadas como amostras do "[...] discurso da própria razão sobre si mesma” (LEBRUN, 2002, p. 13), cujas criaçôes não têm sua origem somente nas ideias do tempo, e sim nas tendências constitutivas e permanentes do próprio espírito humano - que se manifestam de diferentes formas nas estruturas filosóficas, nos sistemas da razão (MOURA, 1988, p. 170). Em outras palavras, quando essa filosofia universitária se sustenta em um pressuposto da racionalidade universal kantiana, considerando a história da filosofia para além de sua determinaçáo social e como paradigma de racionalidade, assume-se a filosofia como um empreendimento de des-historicidade, válido eternamente independente do contexto dos leitores - um ótimo exemplo da racionalidade eurocentrada que sustenta a exclusão de alguns grupos sociais e formas de vida. Assim, opera-se uma cisão entre o contexto e a construção do conhecimento, criando-se uma forma de filosofia acadêmica que insiste em negar à produção filosófica uma história, uma sociedade, problemas e condiçóes de possibilidade. Na realidade, conforme assegura Bourdieu (2007, p. 31), esse é um problema característico das diversas filosofias da História da Filosofia:

As filosofias da História da Filosofia, apesar de sua diversidade, convergem em relação à afirmação da irredutibilidade do discurso filosófico a qualquer determinação social. Se há questão que a filosofia (apesar de tão questionadora) e a História da Filosofia (que a faz surgir por sua própria existência) esforçam-se por excluir é a das condiçôes sociais de possibilidade da Filosofia, do filósofo e dos efeitos filosóficos - por exemplo os limites inconscientes - que estão implicados nessas condiçôes.

Tendo isso em consideraçáo, é preciso questionar o caráter imprescindível, legislador e eterno dos clássicos, afinal, em que medida “[...] o pensamento filosófico alimenta-se preferencialmente de sua própria tradição, a qual fornece os termos de comparação obrigatórios" (ARANTES, 1994, p. 29) para as reflexóes filosóficas atuais? Da forma como se estrutura a pesquisa filosófica nas universidades brasileiras, somos ensinadas/os/es que os problemas de filósofos europeus, aos quais poderíamos incluir alguns poucos estadunidenses de séculos passados, são as referências necessárias ao nosso pensamento. Diversas vezes, esse discurso da universalidade é usado para 
negar a existência de uma filosofia brasileira ou indígena, porém, as mesmas pessoas utilizam as expressóes "filosofia alemã" ou "filosofia francesa", a fim de contextualizar ou validar os argumentos. Por essa razão, faz-se preciso denunciar que essa extrema valorização, principalmente da filosofia europeia - dos clássicos como estrelas fixas que guiam as reflexóes futuras e a história da filosofia como universal e perene -, já pressupóe uma certa filosofia da história da filosofia que se instala na academia e cujos pressupostos destituem a própria importância do contexto na construção problemática e criativa do conhecimento.

Ao contrário disso, pensamos ser essencial conhecer o contexto de emergência de um determinado pensamento para compreendê-lo. Conceitos e contexto têm uma relação intrínseca que não pode ser ignorada, especialmente no âmbito da filosofia, área que se dedica a pensar o contemporâneo. Quando o universal passa a substituir as demandas locais, a filosofia cai em uma abstração exacerbada, distanciando o pensamento da vida, e acaba por não ter condiçóes de olhar para os problemas que a afetam. Pelas enormes diferenças entre a história dos territórios dos países do Norte e nós do Sul, por toda a violência a que europeus submeteram os povos originários e africanos que construíram as Américas, é impossível desconsiderar as consequências de seus pensamentos, principalmente os seus pressupostos colonizadores, em nossas vidas. Ao optarmos pela universalidade, corremos o risco de dar continuidade às teorias e imagens, cujos pressupostos legitimam as práticas violentas, responsáveis por delinear um ideal de humanidade eurocêntrico, através do qual os povos ameríndios e africanos foram submetidos. Fazer uso das filosofias europeias, de maneira abstrata e não territorial, pode nos levar a repetir as relaçôes entre colonizadores e colonizados que, além de náo colaborarem para lidarmos com os desafios que vivenciamos, podem aprofundar, ainda mais, a colonialidade em que estamos imersos.

Para melhor entender as implicaçóes disso, podemos lembrar que a suposta universalidade da categoria "humano" serve para invisibilizar grupos sociais e outras formas de vida. Como pensa Ailton Krenak (2019), a invasão europeia significou a imposição de um modo de vida de separação com a natureza: "[...] fomos nos alienando desse organismo que somos parte, a Terra, e passamos a pensar que ele é uma coisa e nós, outra: a Terra e a humanidade. Eu não percebo onde tem alguma coisa que não seja natureza. Tudo é natureza. $\mathrm{O}$ cosmos é natureza." (KRENAK, 2019, p. 16-17). Nessa perspectiva, inaugurase um "[...] estado de exceção ontológico" (DANOWSKI; VIVEIROS DE 
CASTRO, 2014, p. 43), no qual, em nome de uma suposta racionalidade superior, justifica-se qualquer ação no mundo, tanto a exploração do território quanto daqueles sujeitos que são vistos como mais próximos da natureza do que da humanidade. Aliás, o que a filosofia ocidental concebe por "humano" diz respeito a um indivíduo isolado que, apesar de se relacionar com outros e com a natureza, continua cercado pela redoma da subjetividade - um dentro (sujeito) que se relaciona com um fora (objeto). Ao contrário disso, como os estudos da biologia demonstram, somos compostos por um emaranhado multiespécie sem o qual não poderíamos sequer sobreviver. Nessa esteira, Krenak (2019, p. 69-70), referindo-se à nossa relação com a natureza, propóe:

Devíamos admitir a natureza como uma imensa multidão de formas, incluindo cada pedaço de nós, que somos parte de tudo: $70 \%$ de água e um monte de outros materiais que nos compóem. E nós criamos essa abstração de unidade, o homem como medida das coisas, e saímos por aí atropelando tudo, num convencimento geral até que todos aceitem que existe uma humanidade com a qual se identificam, agindo no mundo à nossa disposição, pegando o que a gente quiser. Esse contato com outra possibilidade implica escutar, sentir, cheirar, inspirar, expirar aquelas camadas do que ficou fora da gente como "natureza", mas que por alguma razão ainda se confunde com ela. Tem alguma coisa dessas camadas que é quase-humana: uma camada identificada por nós que está sumindo, que está sendo exterminada da interface de humanos muito-humanos. Os quase-humanos são milhares de pessoas que insistem em ficar fora dessa dança civilizada, da técnica, do controle do planeta. E por dançar uma coreografia estranha são tirados de cena, por epidemias, pobreza, fome, violência dirigida.

A conceituação feita por Krenak, ameríndia portanto, estabelece outros modos de pensar a relação humano-natureza, e evidencia uma maneira de entender a cosmologia radicalmente diferente da perspectiva ocidental hegemônica. A construção conceitual ecológica, no Ocidente, mantém um vínculo com certa cosmopolítica, responsável por fomentar a fragmentação, uma racionalidade que sustenta uma relação simbólica e dualista com o ambiente. Tal dualidade só pode existir abstratamente, pois diferentes escalas, da micro à macro, apontam para relaçôes emaranhadas entre seres e ambientes, uma relação imanente. Isso também nos demonstra que os problemas e a própria construçáo conceitual não se dão de forma neutra, porque carregam pressupostos de uma cosmovisão específica, desenvolvendo um papel fundamental de significação do mundo e da realidade. 
A filósofa Lélia Gonzalez tem enormes contribuiçôes nesse sentido, apesar de raramente ser lembrada nas produçóes teóricas e nos debates acadêmicos em filosofia. Gonzalez chama a atenção para a necessidade de pensarmos teorias e práticas, tendo como referência o contexto da América Latina e do Brasil. Embora alguns filósofos indiquem a necessidade de pensarmos desde o Brasil (CABRERA, 2013), a obra de Gonzalez mostra que isto não é suficiente.

De fato, precisamos criar nossos próprios conceitos, porque aqui existem muitas ideologias - como o mito da democracia racial e os exemplos supracitados - que modelam nossa maneira de ver a realidade e nos impedem de compreender as relaçóes históricas de poder que nos atravessam. Basta lembrar, por exemplo, que "América" é uma homenagem ao invasor Américo Vespúcio, assim como "brasileiro" consiste em uma referência a quem comercializava pau-brasil. Em ambos os casos, identifica-se um vínculo exploratório com o ambiente e com os sujeitos, algo totalmente contrário ao pensamento dos povos originários massacrados pela colonização. Por isso, as filosofias ameríndias propóem o conceito Abya Yala para se referir ao nosso continente, haja vista que essa compreensão é anterior aos invasores, além de defenderem filosofias sustentáveis na relação com o ambiente, muito antes da colonização.

O patriotismo, que é empurrado à força para a população, tem, em seu cerne, uma visão de "Brasil" que não leva em consideração as pessoas que aqui vivem e muito menos as que viveram anteriormente à invasão europeia. O "brasileiro" representa aquele que serve aos interesses exploratórios do território. Olhar para essa faceta de "ordem e progresso" com orgulho nos impede, muitas vezes, de enxergar os pressupostos e os valores que nos tornam aquilo que somos. O mesmo ocorre com a palavra "índio", que carrega consigo a ideologia eurocêntrica sobre os povos que aqui viviam quando o território foi invadido. Tal termo se originou por uma visão deturpada dos europeus, e nos impede de ver quem são os povos ameríndios que vivem aqui, afirmando uma série de pressupostos a partir dos quais, dentre outras consequências, são encobertos os mais de 250 povos existentes no território e desenhada uma visão sobre eles caricatural e estática no tempo. De fato, o conceito de “indígena”, "aquele que é da terra, nativo do território", é mais adequado para nos referirmos a tais povos. Isso leva Enrique Dussel (1993) a afirmar que nunca houve encontro ou descobrimento, mas sim encobrimento dos povos originários, habitantes daqui muito antes de 1492. 
A aceitação e a utilização de categorias criadas sobre nós, sem refletirmos profundamente a respeito das relaçóes éticas, políticas e epistemológicas que as sustentam, conduz-nos à dificuldade de construirmos um pensamento enraizado com a história e contexto de dominação dos quais fazemos parte. Por essa razão, cabe lembrar as palavras, com as quais concordamos, da boliviana Silvia Rivera Cusicanqui (2010, p. 19, tradução nossa): "Há no colonialismo uma função muito peculiar para as palavras: elas não designam, e sim encobrem”.

Encobertos pelos pressupostos e práticas coloniais, não é sem razão que, quando há a mínima possibilidade de ensaiarmos uma problematização daquilo que nos afeta em nosso território, sentimos muita dificuldade. Acostumados a creditar à história da filosofia suas qualidades universais e, portanto, descontextualizada de nosso tempo-espaço, queremos "encontrar" os problemas de nosso tempo nos livros da biblioteca e nos escaninhos eternos da história, sufocando a nossa realidade pelos esquadrinhamentos dos escritos do Norte global. Nessas condiçôes, atribuímos ao pensamento filosófico uma condição de fórmula: um quebra-cabeça a partir do qual precisamos encontrar as peças certas para delimitar os contornos de nossa realidade. No entanto, o que de fato fazemos é sequestrar nossa capacidade de pensar, de forma a trabalhar com imagens representacionais que, ao darem significado às nossas experiências, reproduzem os pressupostos hegemônicos responsáveis pela dominação e visão de mundo eurocêntrica. É como se olhássemos para os discursos e pressupostos construídos por filósofos europeus de séculos passados para encontrar uma série de categorias que determine o sentido da realidade da qual fazemos parte. E isso, nas raras ocasióes em que o nosso tempo é posto em questão.

Considerando que a produção de conhecimento, no Brasil, é eurocentrada, Lélia Gonzalez tentou romper com as categorias com as quais certa elite intelectual se empenhou, e continua se empenhando, em imprimir como verdade, propondo o conceito de amefricanidade para evidenciar uma maneira de pensar que circula no (sub)mundo, desliza no dia a dia das ruas e - por que não? - nos corredores das universidades, onde a vida ainda é colocada em questão. Como destaca Gonzalez (1988, p. 72), a América Latina é "[...] muito mais ameríndia e amefricana do que outra coisa", mesmo que isso seja invisibilizado. Quando pensamos no Brasil, tal apagamento é ainda mais grave, pois é o país com a maior população negra fora do continente africano, compondo mais da metade da população nacional, além de contar 
com mais de 250 etnias indígenas. Por isso, a filósofa propõe compreendermos nosso território por meio do conceito "Améfrica Ladina" (1988, p. 69):

\begin{abstract}
Trata-se de um olhar novo e criativo no enfoque da formação históricocultural do Brasil que, por razōes de ordem geográfica e, sobretudo, da ordem do inconsciente, não vem a ser o que geralmente se afirma: um país cujas formações do inconsciente são exclusivamente européias, brancas. Ao contrário, é uma América Africana cuja latinidade, por inexistente, teve trocado o $t$ pelo $d$ para, aí sim, ter o seu nome assumido com todas as letras: Améfrica Ladina (não é por acaso que a neurose cultural brasileira tem no racismo o seu sintoma por excelência). Nesse contexto, todos os brasileiros (e não apenas os "pretos" e os "pardos" do IBGE) são ladinoamefricanos.
\end{abstract}

A proposta de Gonzalez não é meramente uma troca de termos. Questionar as denominaçóes que foram impostas aos povos deste continente e criar outras formas de nomear o território e a população implicam olhar através de outras perspectivas. Améfrica Ladina é um conceito que evidencia um pensamento que parte de um contexto, mas não só, destaca também a importância dos povos de origem africana para a construção do continente e o apagamento deles na produção de conhecimento como um todo. No mesmo sentido, Gonzalez (1988, p. 70) aponta para o "pretuguês", correspondente à "marca de africanização do português falado no Brasil", expressando, no imaginário e na alteração da pronúncia, as cosmovisões dos povos de origem africanas.

Além disso, as heranças de povos africanos, e também ameríndia, na cultura do território chamado de "Brasil" estão para além da língua: sua presença é marcante nos costumes e em todas as áreas relevantes. No entanto, "[...] tudo isso é encoberto pelo véu ideológico do branqueamento, é recalcado por classificaçóes eurocêntricas do tipo "cultura popular", "folclore nacional" etc., que minimizam a importância da "contribuição negra” à constituição daquilo que somos como população e território (GONZALEZ, 1988, p. 70). Afora a demarcação da substancialidade dos povos de origem africana e ameríndios na constituição de nosso território, a categoria político-cultural da amefricanidade se faz necessária porque as experiências vividas pela população negra, no Brasil, são muito diferentes: por um lado, elas diferem das experiências daqueles que permaneceram no continente africano, de tal modo que os amefricanos não são nem mesmo considerados por estes últimos como "verdadeiros africanos"; por outro lado, conforme explica Gonzalez, o racismo "à brasileira” tem diferenças fundamentais com 
o de outros territórios. Temos, neste país, o melhor exemplo de racismo por denegação, que tem como herança o "mito da democracia racial" e, através de ideologias que escondem o racismo no cotidiano, produz a sua forma mais eficaz por meio da "[...] internalização da 'superioridade' do colonizador pelos colonizados.” (GONZALEZ, 1988, p. 72).

Desse modo, embora os sistemas de dominação sejam racistas em todas as sociedades, Gonzalez chama a atenção para a necessidade de pensar o racismo a partir da "Améfrica Ladina" e do "Brasil", desde uma produção filosófico-conceitual que emerge e expresse as condiçóes de nosso território. Uma vez que há diferenças nos problemas, de acordo com a historicidade de cada território, precisamos tomar cuidado com a apropriação e aplicação formulática de quaisquer conceitos. Este é o caso de muitos estudos que se apoiam, por exemplo, nas teorias estadunidenses, grande maioria nos debates raciais. A questão é que elas podem não ser suficientes para entender a nossa realidade, majoritariamente amefricana e ameríndia. Aliás, até mesmo a expressáo "americanos", usada no Brasil para designar os estadunidenses, mostra o quanto nossa linguagem tenta encobrir a realidade ladinoamefricana, como se os Estados Unidos fossem uma categoria superior, no que diz respeito às Américas, o que se torna extremamente prejudicial para a construção de nossos pensamentos e práticas.

Acreditamos que Gonzalez consegue demonstrar, com o conceito de Améfrica Ladina, a necessidade de a criaçáo conceitual ser consequência da imanência territorial na qual habitamos. Uma prática filosófica que procure construir seus conceitos para estar conectada à sua contemporaneidade não pode prescindir das relaçóes e tensões emergentes com nossa realidade. Os esforços conceituais dessa filósofa se coadunam com os de Krenak, principalmente quando este denuncia e mostra as diferentes visóes de mundo e pressupostos circunscritos à cultura dos colonizadores e dos povos colonizados. Ambos, entáo, nos ajudam a problematizar o pressuposto de uma racionalidade universal, que tem como modelo os conhecimentos e valores construídos e consolidados na Europa e, em menor propensão nos Estados Unidos. Como frisamos, com a filósofa Silvia Rivera Cusicanqui, os saberes e as práticas dos colonizadores encobrem e silenciam os povos colonizados, expressando ainda as relaçóes de dominação que invadem e se capilarizam em nossas instituiçôes e, mais especificamente, em nossas práticas acadêmicas com a filosofia. De acordo com aquilo que demonstramos, não há neutralidade filosófica em tais conhecimentos, e sim uma visão de mundo, cujas práticas foram construídas a 
partir da exploração de povos e, consequentemente, exclusão de outras formas e possibilidades de vida. Essas críticas justificam e potencializam a construção de uma outra forma de conhecimento, marcada por um território e seus contornos contextuais e problemáticos. Para tanto, não será suficiente apenas alterarmos os referenciais teóricos, imigrar do Norte para o Sul. Trata-se, fundamentalmente, de uma mudança de atitude com a filosofia.

Iniciamos este artigo apontando que, no Brasil, encontramos uma recusa em pensarmos nos nossos próprios problemas. Não entendemos a recusa em seu estrito aspecto volitivo, mas a analisamos desde a capilarizaçáo das relaçóes da colonialidade de poder instaladas em nosso território e instituição filosófica. Por essa razão, acreditamos que a participação da filosofia nos debates contemporâneos, conforme desenvolvido até aqui, deve envolver, principalmente, uma nova relação com a nossa própria vida e contexto, deslocando-nos desses pressupostos que condicionam à filosofia do Norte um caráter perene e universal. Com o argumento de "não arrombar portas abertas", como se a história ocidental, europeia por excelência, permeada pelos textos clássicos, representassem o ajuste progressivo da universalidade, impôs-se a necessidade de se constituir uma pesquisa acadêmica circunscrita à explicação e interpretação das filosofias do Norte. Tal relação subalterna permeia hegemonicamente nossa produção de conhecimento de tal forma que, mesmo nas raras situaçóes de estudo de filósofos/as/es brasileiros/as/es ou latino-americanos/as/es, mantêm-se muitos de seus pressupostos e práticas.

A iniciativa da Revista Trans/Form/Ação de incentivar "abordagens filosóficas pós-coloniais, relativas ao continente africano assim como à diáspora e aos desafios similares enfrentados pelos países latino-americanos", embora abra caminhos para uma mudança de perspectiva na filosofia acadêmica, não é suficiente para romper com os principais elementos colonializantes do pensamento em nosso território. Na realidade, grande parte dos estudos entendidos como "decoloniais" não tem se dedicado a refletir sobre o colonialismo interno. Como buscamos apontar, nas páginas anteriores, nascer em território brasileiro - e também africano ou latino-americano em geral não é suficiente para uma filosofia do Sul constituir-se, pois as metodologias empregadas e seus pressupostos podem ser ferramentas de colonialidade. Dessa forma, tanto o pesquisador pode reproduzir uma maneira colonizada 
e subalterna de estudo, apenas repetindo os argumentos ou assimilando-os a categorias eurocêntricas, como também a própria filosofia que emerge do Sul global pode reproduzir estruturas colonializantes. A colonialidade é o que estrutura o sistema-mundo em que vivemos, de forma que a própria expressão "abordagens pós-coloniais", conforme consta na chamada da Revista, pode cumprir o papel de um conceito encobridor, haja vista que a realidade nunca deixou de ser colonizada, como evidenciamos com Quijano e sua proposta acerca da colonialidade do poder. Como a questão geográfica não é suficiente para uma transformação do pensamento, é preciso repensar profundamente as estruturas sociais e o contexto de emergência das nossas práticas filosóficas e dos saberes para além das estruturas internas de um texto.

Se mantivermos as filosofias do Sul numa posição de objeto de estudo, repetindo uma relação sedimentada em nossas atitudes face aos filósofos, corremos o risco ainda de perpetuar a mentalidade colonial e extrativista. A lógica do capitalismo - face oculta da colonialidade - é baseada na extração e assimilação. Os povos vítimas da colonizaçáo sempre foram vistos como recurso. Suas terras, as pessoas, todos os seres do seu território, a sua cultura e conhecimento, tudo isto é visto como recurso de exploração para manter esse sistema. Isso significa que, dentro dos diversos projetos das filosofias do Sul, cabe aos pesquisadores refletirem se suas práticas contribuem para uma transformação da sociedade, descolonizandonos, ou se apenas continuam o projeto colonialista, através do extrativismo epistêmico (GROSFOGUEL, 2016).

Conforme explica Leanne Betasamosake Simpson (KLEIN, 2012, n.p. $)^{9}$, "[...] o ato de extraçáo remove todos os relacionamentos que dão sentido ao que está sendo extraído. Extrair é [...] tomar sem consentimento, sem pensamento, cuidado ou mesmo conhecimento dos impactos que a extração tem sobre os outros seres vivos naquele ambiente." (KLEIN, 2012, n.p., tradução nossa). O extrativismo epistêmico ocorre quando a relação acadêmica com os saberes do Sul global se mantém sob a lógica colonizadora e extrativista. Argumenta Simpson:

Quando houve um esforço para trazer o conhecimento tradicional para o pensamento ambiental após Nosso Futuro Comum, [um relatório emitido pela Comissão Mundial das Nações Unidas sobre Meio Ambiente e Desenvolvimento] no final dos anos 80 , tratou-se de uma abordagem muito

\footnotetext{
${ }^{9}$ Nossa referência é uma entrevista que ela concedeu a Naomi Klein, em 2012, disponível em http:// www.yesmagazine.org/peace-justice/dancing-the-world-into-being-a-conversation-with-idle-nomore-leannesimpson.
} 
extrativista: "Tomemos quaisquer ensinamentos que vocês poderiam ter que nos servissem fora de seu contexto, longe de seus detentores de saber, fora de sua língua e os integrassem nessa mentalidade assimilacionista.” É a ideia de que o conhecimento tradicional e os povos indígenas têm algum tipo de segredo de como viver na terra, de uma maneira náo exploradora, da qual a sociedade em geral precisa se apropriar. Mas a mentalidade extrativista não é sobre ter uma conversa, dialogar e trazer conhecimento indígena, nos termos dos povos indígenas. Trata-se muito mais de extrair quaisquer ideias que os cientistas ou ambientalistas considerassem boas e assimilá-las. (KLEIN, 2012, n.p., tradução nossa).

Quando estudamos tais filosofias sem refletir sobre as relações políticas que as permeiam e sem compromisso com suas demandas, não contribuímos para mudança alguma. Nessa perspectiva, seu estudo serve apenas para que pesquisadores ganhem capital simbólico, publicação de artigos, convites para palestras em países do Norte global, e não para mudanças estruturais necessárias para a descolonização. Não é coincidência que, quase na totalidade, os filósofos latino-americanos, tidos como leitura obrigatória para os estudos decolonias - pertencentes ao grupo de pesquisa conhecido como Modernidadel Colonialidade -, são homens e/ou brancos, sendo que grande parte deles desenvolveu seus estudos em universidades do Norte global.

Combater uma relação extrativista significa, por um lado, operar em outra perspectiva eurocêntrica e academicista, para a qual a filosofia é apenas uma atividade individualista e que olha para a realidade como se tivesse distante dela. Por outro lado, significa se organizar diferentemente da perspectiva culturalista dos estudos decoloniais, que descontextualiza os saberes do Sul, aplicando-os em um contexto diverso, de modo romantizado, sem levar em conta que há relaçôes de opressão também nesses territórios. Afinal, as relaçóes de poder são tão importantes quanto as geográficas e, por essa razão, precisam ser pensadas de modo articulado.

Dentro desse contexto, a fala de Simpson arremata nossas críticas (KLEIN, 2012, n.p., tradução nossa): "O que está faltando é a responsabilidade. [...] Se você for forçado a permanecer no raio de 80 quilômetros, experimentará os impactos do comportamento extrativista." O que nos falta é, ainda de acordo com Grosfoguel (2016), a reciprocidade no diálogo intercultural. A descolonização profunda significa ver os povos do Sul global como agentes da própria história, que pensam e produzem saberes válidos e modos próprios de existência e, portanto, que falam por si mesmos. Caso contrário, nossas pesquisas 
podem servir de instrumentos para mais extrativismo de seus territórios, oferecendo ferramentas para intençóes mercadológicas sobre tais povos.

Dessa forma, é preciso romper com a visão de distanciamento com o objeto de pesquisa, ao mesmo tempo que devemos estar vivenciando, de fato, os problemas que estudamos, a fim de que tenhamos clareza das consequências dos saberes que produzimos. Assim, apontamos para a necessidade de uma descolonização, em que o estudo das filosofias do Sul signifique uma profunda mudança nas nossas açóes, para não recairmos num discurso "despolitizado da alteridade" (CUSICANQUI, 2010, p. 64, tradução nossa), como explica Cusicanqui (2010, p. 62, tradução nossa):

Não pode haver discurso da descolonização, uma teoria da descolonização, sem uma prática descolonizadora. $\mathrm{O}$ discurso do multiculturalismo e o discurso da hibridez [...] encobrem e renovam práticas de colonização e subalternização eficazes. Sua função é suplantar as populaçóes indígenas como sujeitos da história, converter suas lutas e demandas em ingredientes de uma reengenharia cultural e estatal, capaz de submetê-los a sua vontade neutralizadora. Uma "mudança para que nada mude" que dá reconhecimento retórico.

Para descolonizar, é necessário alterar profundamente a forma com que produzimos e nos relacionamos com os saberes, a fim de não perpetuarmos uma "[...] versão logocêntrica e nominalista da descolonizaçáo" (CUSICANQUI, 2010, p. 64, tradução nossa), isto é, uma "[...] mudança para que nada mude". O que adianta uma filosofia no Sul, cuja expressão seja uma racionalidade e uma característica discursiva feita à imagem e semelhança das filosofias do Norte, em que só se considera aquilo que pode ser enquadrado nas representaçóes e funcionamento das lógicas eurocêntricas? Para isso, o estudo e a criação de filosofias do Sul não podem ser feitos na mesma lógica alheia à vida própria, circunscrita à prática hegemônica da filosofia acadêmica no Brasil, que insiste em reduzir a potencialidade de suas pesquisas à interpretação e explicação inclusive das filosofias do Sul, como demonstram alguns casos dos estudos decoloniais. Precisamos olhar tanto para as relaçóes estruturais e sistêmicas que nos cercam quanto as que envolvem os saberes que estudamos para além do que está escrito em um texto, de forma a pensarmos os problemas que nos afetam e como as mais diversas filosofias podem nos ajudar.

Em um contexto de crise, como vivemos atualmente, precisamos repensar o papel desempenhado pelas pesquisas acadêmicas e, especialmente, 
pela filosofia, haja vista, como viemos sustentando nesse artigo, a possibilidade dessa área do saber para pensar a própria contemporaneidade. Contudo, os desafios éticos e políticos das filosofias, que emergem no território em que vivemos, vão além de uma mudança epistemológica, pois, conforme os ensinamentos das filosofias do Sul, pensar nossa realidade significa repensar as categorias que sustentam o que entendemos do mundo, do conhecimento e da própria filosofia, para que não sejamos encobertos por relaçôes dominadoras. Envolve, assim, pensar os problemas do nosso contexto, procurando enxergar quem nos tornamos e transformar nossa forma de nos relacionar com o mundo: caso contrário, faremos uma filosofia para que nada mude.

GELAMO, R. P.; GARCIA, A. V.; RODRIGUES, A. Decolonizing brazilian philosophy: ethical and political challenges for philosophies of the global south. Trans/Form/Açáo, Marília, v. 45, p. 415-438, 2022. Edição Especial.

\begin{abstract}
The goal of this article is to problematize some of the main practices of Brazilian university philosophy, in order to denounce its colonizing assumptions and point out its limits to elaborate a philosophical thought capable of relating, effectively, with the problems that affect us in the Brazilian territory. We will analyze how the strategy of reading and explaining European and unitedstatian texts, predominantly considered the classic references to philosophy, operate the relations of knowledge and domination that exist between the global North under the peoples of the South that they colonized. We will use the constitutive experience of the degree in philosophy at the University of São Paulo as an example of the practices and assumptions of coloniality by which our academic philosophy is modeled. From the contributions of Lélia Gonzalez (1988), Ailton Krenak (2019), Silvia Rivera Cusicanqui (2010) and Leanne Betasamosake Simpson (KLEIN, 2012), we will question those practices and assumptions, demonstrating how these authors challenge us not only to change the usual theoretical framework naturalized in Brazilian philosophy, but, above all, to operate an ethical and political change in the relationships that we usually establish with philosophy.
\end{abstract}

Keywords: Brazilian philosophy. Coloniality. University practices. Historiography.

\title{
REFERÊNCIAS
}

ARANTES, Paulo Eduardo. Um departamento francês de Ultramar: estudos sobre a formação da cultura filosófica uspiana. Rio de Janeiro: Paz e Terra, 1994.

BALLESTRIN, Luciana Maria de Aragão. Modernidade/Colonialidade sem "Imperialidade"? O Elo Perdido do Giro Decolonial. Revista de Ciências Sociais, Rio de Janeiro, v. 60, n. 2, p. 505-540, 2017. 
BOURDIEU, Pierre. As ciências sociais e a filosofia. Trad. José Luiz Fiorin. Educação \& Linguagem, ano 10, n. 6, p. 19-36, jul./dez. 2007.

BRASIL. Conselho Nacional de Educação. Resoluçáo CEB no 3/1998. Diretrizes Curriculares Nacionais para o Ensino Médio. Diário Oficial, Poder Executivo, Brasília, 1998. Disponível em: http://portal.mec.gov.br/cne/arquivos/pdf/rceb03_98.pdf. Acesso em: 25 jun. 2020.

BRASIL. Secretaria da Educação Média e Tecnológica. Parâmetros Curriculares Nacionais: ensino médio. Brasília: MEC; SEMTEC, 2002.

BRASIL. Secretaria de Educação Básica. Orientaçóes Curriculares para o Ensino Médio: Ciências Humanas e suas tecnologias (Ocem). Brasília: MEC; SEB, 2006. Disponível em: http://portal.mec.gov.br/ seb/arquivos/pdf/book_volume_03_internet. pdf. Acesso em: 12 mar. 2020.

CABRERA, Julio. Diário de um filósofo no Brasil. 2. ed. Ijuí: Ed. Unijuí, 2013.

CUSICANQUI, Silvia Rivera. Ch'ixinakak utxiwa: una reflexión sobre prácticas y discursos descolonizadores. Buenos Aires: Tinta Limón, 2010.

DANOWSKI, Débora; VIVEIROS DE CASTRO, Eduardo. Há mundo por vir? Ensaio sobre os medos e os fins. Florianópolis: Cultura e Barbárie; Instituto Socioambiental, 2014.

DUSSEL, Enrique. 1492: o encobrimento do outro - a origem do mito da modernidade. Petrópolis: Vozes, 1993.

GOLDSCHMIDT, Victor. Tempo histórico e tempo lógico na interpretação dos sistemas filosóficos. Trad. Oswaldo Porchat. In: GOLDSCHMIDT, Victor. A religiáo de Platáo. São Paulo: Difusão Europeia do Livro, 1970. p.139-147.

GONZALEZ, Lélia. A categoria político-cultural da amefricanidade. Tempo Brasileiro, Rio de Janeiro, n. 92-93, jan./jun. 1988.

GROSFOGUEL, Ramón. Del extractivismo económico al extractivismo epistémico y al extractivismo ontológico: una forma destructiva de conocer, ser y estar en el mundo. Tabula Rasa, Bogotá - Colômbia, n. 24, p. 123-143, enero/jun. 2016.

GUÉROULT, Martial. O problema da legitimidade da história da filosofia. Revista de História, São Paulo, v. 37, n. 75, p. 189-211, [1956] 1968. Disponível em: http://www. revistas.usp.br/revhistoria/ article/view/128471/125316. Acesso em: 6 abr. 2020.

HEGEL, George W. F. [1837] Lecciones sobre la filosofía de la historia universal. Madrid: Alianza, 1982.

KLEIN, Naomi. Dancing the World into Being: A Conversation with Idle-NoMore's Leanne Simpson. Yes Magazine, March 5, 2012. Disponível em: http://www. yesmagazine.org/ peace-justice/dancing-the-world-into-being-a-conversation-with-idleno-more-leannesimpson. Acesso em: 4 maio 2020. 
LEBRUN, Gérard. Kant e o fim da metafísica. Trad. Carlos Alberto Ribeiro de Moura. 2. ed. São Paulo: Martins Fontes, [1970] 2002.

MARGUTTI, Paulo Roberto. A história da filosofia do Brasil (1500-hoje): $1^{\text {a }}$ parte: o período colonial (1500-1822). São Paulo: Loyola, 2013.

MARGUTTI, Paulo Roberto. Sobre a nossa tradição exegética e a necessidade de uma reavaliação do ensino de Filosofia no país. Kriterion, Belo Horizonte , v. 55, n. 129, p. 397-410, jan./jun, 2014. Disponível em: http://www.scielo.br/scielo.php?script=sci_ arttext\&pid=S0100 512X2014000100024\&lng=en\&nrm=iso. acesso em: 15 jul. 2020.

MARQUES, Ubirajara Rancan de Azevedo. A escola francesa de historiografia da Filosofia: notas históricas e elementos de formação. São Paulo: Editora UNESP, 2007.

MAUGÜÉ, Jean. O ensino da filosofia: suas diretrizes. Revista Brasileira de Filosofia, Sáo Paulo, v. 4, fasc. IV, p. 642, 1955.

MOURA, Carlos Alberto Ribeiro de. História stultitiae e história sapientiae. Discurso, São Paulo, v.17, p.151-72, 1988. Disponível em: http://www.revistas.usp.br/discurso/ article/view/37935. Acesso em: 05 jun. 2020.

PALÁCIOS, Gonzalo Armijos. Ensino da filosofia no Brasil. Revista Sul-Americana de Filosofia e Educaçáo. Brasília, n. 1, p. 1-16, nov./2003-abr./2004.

PALÁCIOS, Gonzalo Armijos. Filosofar e ensinar a filosofar. In: SARDI, Sérgio Augusto; SOUZA, Draiton Gonzaga de; CARBONARA, Vanderlei (org.). Filosofia e sociedade: perspectivas para o ensino de filosofia. Ijuí: Ed. Unijuí, 2007. p. 103-113.

PRADO JÚNIOR, Bento. As filosofias da Maria Antônia (1956-1959) na Memória de um Ex-Aluno. In: SANTOS, Maria Cecília Loschiavo (org.). Maria Antônia: uma rua na contramão. São Paulo: Nobel, 1988. p. 66-81.

QUIJANO, Aníbal. Colonialidade do poder, eurocentrismo e América Latina. In: A colonialidade do saber: eurocentrismo e ciências sociais. In: LANDER, Edgardo (org.). Buenos Aires: Conselho Latino-Americano de Ciências Sociais - CLACSO, 2005.

RIBEIRO, Renato Janine. Pode o Brasil renunciar a filosofar? In: SOUZA, José Crisóstomo de. A filosofia entre nós. Ijuí: Editora Uniju, 2005. p. 89-108.

RIBEIRO, Renato Janine. A universidade e a vida atual: Fellini náo via filmes. 2. ed. São Paulo: Editora da Universidade de São Paulo, 2014.

SANTOS, Boaventura de Souza. Um ocidente não-ocidentalista? A filosofia à venda, a douta ignorância e a posta de Pascal. In: SANTOS, Boaventura de Souza; MENESES, Maria Paula (org.). Epistemologias do Sul. São Paulo: Cortez, 2010. p. 519-562.

Recebido: 21/01/2020

Aceito: $12 / 8 / 2020$ 